\title{
Keeping up with the journals
}

\author{
With more and more scientific articles and journals being published, how can you effectively keep \\ abreast of new research relevant to your own projects?
}

The ever-increasing number of chemistryrelated journals and articles has been discussed and debated for years ${ }^{1-5}$. Usually the focus falls on three issues: the increase in the overall number of articles, the increase in the number of (usually more specialized) journals, and the fragmentation of results by researchers to maximize their number of publications. The first issue is easy to explain: there are simply more scientists now and they all depend critically upon the publication of their work. Few scientists would argue against more science and this issue seems here to stay.

The increase in the number of specialized journals is a more contentious matter. In 1973, a group of eleven concerned chemists (which contained 'recent' Nobelists Geoffrey Wilkinson and Har Gobind Khorana, and future Laureates Roald Hoffmann and Jean-Marie Lehn), lamented the "recent proliferation of journals" . They raised concerns about commercial journals, their high subscription fees, their apparent low standards and their drive towards compartmentalizing chemistry. They argued that "the literature should be so constructed as to deter trends towards overspecialization, and should foster communication among chemists working in different areas".

The sentiment about improving interdisciplinary communication is admirable, but the general growth in the number of publications makes it unrealistic to expect researchers to keep up with current studies by reading only a few select journals. Compartmentalization was an inevitability that has some sound logic behind it - researchers can read specialist journals knowing that they will find papers of interest and can publish in them assured that their peers will be more likely to see their work. The associated benefits of creating niche journals are perhaps lost, however, if each publisher has their own outlet in any given speciality.

Fragmentation of results is also often mentioned when discussing the literature, and perhaps this is more of an issue today than in the past because of the direct link between how scientists are evaluated and the number of papers they have published. The increasing reliance on metrics to evaluate the 'quality' of a given researcher or project has intensified the publish-or-perish atmosphere within academia. Rapid publication is important for scientific advance but it must be balanced against the urge to split one's work into what have been called the "least publishable units"

With the literature now so vast, keeping abreast of what is going on in a given scientific field has become a real challenge, but remains an important aspect of practising cuttingedge science. Not knowing about a published paper relevant to your research can have detrimental consequences when trying to get published or funded. Repeating the work of others, although occasionally worthwhile to validate a contentious point, is not the goal of most innovative researchers. Although some researchers browse the literature retrospectively — each time they write a funding proposal or an article - actively keeping up to date with the literature can have obvious benefits, but it is a daunting task.

Taking a physical chemist as an example, if they were to look through a selection of broad chemistry journals and all of the specialized physical chemistry journals for papers relevant to their research, they would have approximately 2,000 articles to browse each month. This situation is obviously unmanageable and does not even include journals dedicated to interdisciplinary fields such as nanotechnology or analytical chemistry, in which physical chemists may also take a keen interest

Keeping informed of current developments in the literature has always been a challenge, but previously the problems were more related to the limited communication platforms available - print and word-of-mouth - rather than the huge number of articles being published. This all changed with the rise of the internet, which provided a discrete leap forward in the way in which we communicate. It has also served as a catalyst for the increase in articles, with the costs to publishers involved in creating and running new or bigger journals diminishing as technology has improved.

Technology might have exacerbated the problem, but it is has also offered tools that allow people to track the literature in new ways. The Nature Chemistry editors all use RSS feeds with a feed reader that allows papers to be shared among the team. You subscribe to the feeds of journals and when they publish an article the feed is updated. This might sound just like an e-mail alert or like browsing the journal website, but RSS feeds are far more straghtforward to organize, track and search. This makes it easier to find articles on specific topics and to share articles amongst invited group members, reducing the chance of missing relevant papers. RSS feeds that alert you to recently published papers citing a specific article can also be created through Web of Science or Scopus and is a superb method by which to follow current research on specific key topics.

There are other online tools that can be used in a similar way. Twitter, as a rapid online information exchange, is a great way of keeping up to date with news of more general scientific interest, but unless your research community is actively using it to swap interesting papers, it is much less useful for keeping track of more specialized areas. Online reference-management programmes such as Connotea and Mendeley also have the facility to share articles; however, unlike with RSS feeds, you have to find the articles and add them to your database yourself before sharing.

There are obviously busy periods when checking the literature plummets down a researcher's to-do list, but many would be content if they were, at the very least, aware of the most important new articles in their field. The website 'Faculty of 1000' (ref. 6) provides the biomedical community with a place to find them and an equivalent in the chemistry community would be most useful. It relies on academics identifying and evaluating articles from the literature and can, quite quickly, give an idea of which papers are piquing the interest of their peers.

The number of articles being published is growing year-on-year and so, it seems, are the journals in which they are published. Although objections to this are understandable - particularly when it comes to stretched library budgets - the reasons behind it are to a large extent understandable and not wholly undesirable. With a little organization and some useful online tools, the apparently daunting task of keeping up to date can be achieved: like eating an elephant, it has to be done one bite at a time.

\footnotetext{
References

1. Balhausen, C. J. et al. Chem. Eng. News 51, 44 (1973)

2. Replies to Balhausen, C. J. et al. Chem. Eng. News 52, 5-6 (1974).

3. Thompson, H. W. Chem. Eng. News 52, 2 (1974).

4. Verkade, J. G. Chem. Eng. News 60, 40 (1982).

5. Garfield, E. Science Literacy, Policy, Evaluation, and Other Essays 364-367 (Essays of an Information Scientist series 11, Isi, 1988). 6. http://f1000.com/
} 